\title{
Sensorless Brushless DC Motor Control Using Type-2 Fuzzy Logic
}

\author{
Coskucan Buyukyildiz ${ }^{1}$, Ismail Saritas ${ }^{2}$
}

\begin{abstract}
Submitted: 19/10/2020 Accepted : 30/11/2020
Abstract: Brushless DC motors are used in different fields today due to many advantages such as noiseless operation, maintenance cost, efficiency. In recent years, sensorless control techniques related to these engines have been developed and widely used. In addition, conventional controllers do not give the desired results as these motors are non-linear in nature. In this study, the brushless motor was used without a sensor and due to its non-linearity, the Type-2 fuzzy logic controller, which is one of the artificial intelligence techniques, was used to better resolve the uncertainties in the system. In simulation performed in Matlab - Simulink, PID, Type-1 and Type-2 Fuzzy Logic controller results were compared and as a result, it was observed that Type-2 Fuzzy Logic controller gave the most desired response in the system response.
\end{abstract}

Keywords: Type-2 Fuzzy Logic, BLDC Motor, Sensorless Control, Type-1 Fuzzy Logic, PID Controller

\section{Introduction}

A brushless de motor is a kind of synchronous motor which are powered by DC electric current source and BLDC motors, also known as Permanent Magnet DC Synchronous motors or electronically commutated motors (ECMs) with rotor position feedback. The stators of BLDC motors are the coils and the rotors are the permanent magnets. BLDC motors adopt Hall Effect sensors in place of mechanical commutators and brushes. The position of the rotor is detected by these sensors as the commutating signals. Therefore, BLDC motors use permanent magnets instead of coils in the armature and consequently, do not require brushes.

BLDC motors have many advantages over brushed DC motors and induction motors, such as a better speed versus torque characteristics, high dynamic response, high efficiency and reliability, low cost drives, long operating life (no brush erosion), noiseless operation, higher speed ranges, and reduction of electromagnetic interference (EMI). In addition, BLDC motor has less inertia, such that the start and stop of the motor is easier and the ratio of delivered torque to the size of the motor is higher. Because to that fact that led to the application of BLDC motors in a wide variety of commercial and household applications, such as refrigerators, washing machines, personal computers, to military and automotive industry extending to aerospace. Over past few decades, the performance of these motors has significantly increased due to rapid development in power electronics and various commutation techniques.

A BLDC motor requires an inverter and a sensor to achieve commutation process. However, the hall sensor presents quite a few disadvantages from the standpoint of drive's cost, machine size, reliability, temperature sensitivity requiring special arrangements and noise protection. As a result, with the increasing power of embedded computing, the sensorless control method has

\footnotetext{
${ }^{1}$ Mechatronic Eng., Selcuk University, Konya - 42002, TURKEY ORCID ID : 0000-0002-8190-5914

${ }^{2}$ Mechatronic Eng., Selcuk University, Konya - 42002, TURKEY ORCID ID : 0000-0002-5743-4593

* Corresponding Author Email: coskucan94@ hotmail.com, isaritas@selcuk.edu.tr
}

become more popular. Many researches have been reported for sensorless drives that can control position, speed, and torque devoid of shaft-mounted position sensors, in sensorless control technique, various methods are used to detect the instantaneous position of rotor. Those methods can be divided into four categories;

1) Detecting the zero crossing points of the motor terminal to neutral voltage with or without precise phase shift circuit

2) Back electromagnetic force (EMF) integration method

3) Sensing the third harmonic of the back EMF

4) Detecting the freewheeling diode conduction and related extensive strategies.

Among the various techniques, the back EMF zero crossing detection method is the most popular due to its simplicity, easy of implementation, and lower cost. BLDC motors also exhibit two different types of back EMF waveforms; trapezoidal and sinusoidal.

According to those technique, every commutation sequence has one winding energized positive, the second negative, and the third winding is left open. The voltage polarity of Back EMF crosses from positive to negative, or from negative to positive (Zerocrossing), between two commutations. In ideal cases, the zerocrossing of BEMF occurs 30 electrical degrees after the last commutation, and 30 electrical degrees before the next commutation. By measuring the zero-crossing of BEMF and the 30 degrees time interval, the controller can perform the commutation without a position sensor. These square wave pulses hence generated are similar to hall sensors output and so are used to commute the motor.

Linear systems can be expressed mathematically. But in nonlinear systems, it is difficult to express mathematically, as instability and system complexity increase. The basic variables of these motors, such as speed and torque, are linearly dependent on variables such as current and voltage. Also, Uncertainties caused by the change of motor parameters affect the linearity of the system. Therefore, it is difficult to model mathematically. Many techniques for BLDC motor speed control have been developed such as PID, Fuzzy logic controller, adaptive fuzzy logic controller. Conventional PID 
controller, which is a linear control method, is used in many control problems. Because it is easy to implement and have simple structure. However, in practice, conventionally tuned PID controllers do not give satisfy performance [4]. Behavior of fuzzy logic (FLC) is easily understood by a specialist as the knowledge that is expressed using the language rules. Unlike the traditional theory of linear and nonlinear control, FLC is not based on the mathematical model and is widely used to solve problems in areas with a high degree of nonlinearity.

The various techniques discussed gave good response for speed control of BLDC motor. But the responses obtained were oscillatory. Additionally, when a load was applied to these systems, the system's responses were much lower than the reference value. To remove oscillations and achieve a better performance, some new techniques were required. With the development of type- 2 fuzzy logic systems and their ability to handle uncertainty with robust and adaptive structure against complex systems, utilizing type-2 fuzzy logic systems has attracted a lot of interest in recent years.

In this study presents the implementation of type-2 fuzzy logic controller, type-1 fuzzy logic controller and PID controller for speed control of BLDC motor. The control algorithms presented are simulated by use of the MATLAB/Simulink software and the effectiveness of the proposed controller is evaluated. The efficiency of methods was compared with each other.

\section{Material and Methods}

In this study, modeling was done with a real three phase BLDC motor parameters. The motor was controlled without sensors using the back emf signals. The differences between working with type1 fuzzy logic, type- 2 fuzzy logic and PID controller methods in closed loop are revealed. The parameters of the motor are shown in the table below.

Table 1. BLDC motor parameters

\begin{tabular}{|l|c|}
\hline Number of Poles & 8 \\
\hline Number of Phase & 3 \\
\hline Rated Voltage (VDC) & 24 \\
\hline Rated Speed (RPM) & 4000 \\
\hline Continuous Stall Torque (N.m) & 0.3 \\
\hline Rated Torque (N.m) & 0.25 \\
\hline Rated Power (W) & 105 \\
\hline Peak Torque (N.m) & 0.75 \\
\hline Line to Line Resistance (ohm) & 0.28 \\
\hline Line to Line İnductance (Mh) & 0.54 \\
\hline Torque Constant (Nm/A) & 0.0376 \\
\hline Back EMF (Vrms/KRPM) & 2.62 \\
\hline Rotor İnertia (g.cm $\left.{ }^{2}\right)$ & 96 \\
\hline
\end{tabular}

\subsection{Mathematical Model of BLDC Motor}

BLDC motors can be modeled similar to three phase synchronous machine. Permanent magnet is mounted on rotor. Therefore, some dynamic characteristics are different. The self and mutual inductances of all windings are equal. Rotor reluctance and electrical angle is equal. Power semiconductor devices in the inverter are ideal. The motor is not saturated and iron losses are negligible. The stator resistance of all windings are equal. The stator currents are restricted to be balanced and voltage equations of the motor can be defined as follows.
$V_{a}=R i_{a}+L \frac{d i_{a}}{d t}+e_{a}$

$V_{b}=R i_{b}+L \frac{d i_{b}}{d t}+e_{b}$

$V_{c}=R i_{c}+L \frac{d i_{c}}{d t}+e_{c}$

The modelling equations of BLDC motor can be represented in matrix form as represented in equation (4).

$\left[\begin{array}{l}V_{a} \\ V_{b} \\ V_{c}\end{array}\right]=\left[\begin{array}{ccc}R+L \frac{d}{d t} & 0 & 0 \\ 0 & R+L \frac{d}{d t} & 0 \\ 0 & 0 & R+L \frac{d}{d t}\end{array}\right]\left[\begin{array}{l}i_{a} \\ i_{b} \\ i_{c}\end{array}\right]+\left[\begin{array}{l}e_{a} \\ e_{b} \\ e_{c}\end{array}\right]$

Where $L_{a}=L_{b}=L_{c}=L=L_{s}-M$

$L_{s}=$ Armature of self inductance

$M=$ Mutual inductance

$R_{a}=R_{b}=R_{c}=R=$ armature resistance in ohm

$V_{a}, V_{b}, V_{c}=$ terminal phase voltage in volts

$i_{a}, i_{b}, i_{c}=$ motor input current in ampers

$e_{a}, e_{b}, e_{c}=$ motor back emf in volts

\subsection{Type-2 Fuzzy Logic}

The main point on which the fuzzy control systems are based is that an expert system operator creates the knowledge, experience, intuition and control strategy as a knowledge base. Control operations are not performed with complex and classical control algorithms. It is carried out by verbal rules based on knowledge and experience. In this sense, the success of type-1 fuzzy logic systems led to the development of fuzzy logic systems based on type-2 fuzzy sets. The structure of these systems includes fuzzifier, fuzzy inference process and defuzzifier as in type-1 fuzzy logic systems. Unlike type-2 fuzzy logic systems, there is an additional step in the defuzzifier. After this stage, type-2 fuzzy sets are converted to an equivalent type-1 fuzzy set. This process is carried out with the type reduction algorithm and the block diagram is shown in Figure. 1 The accuracy of the type reduction process varies depending on the number of points evaluated in the input area of fuzzy sets. The more these points are used, the better results come out but the computational complexity increases. Therefore, type-2 fuzzy sets are used to overcome this problem. These sets can also be represented as triangle, gauss or trapezoidal membership function.

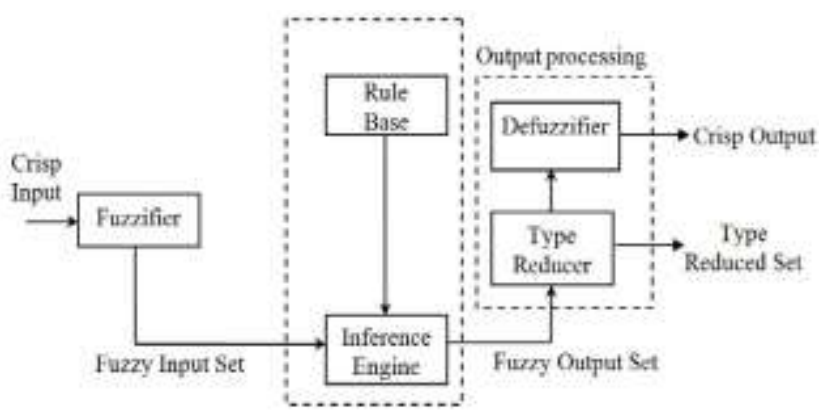

Fig 1. Type-2 fuzzy logic controller block diagram 
Type-2 fuzzy sets were developed by Zadeh in 1975 as an extension of type-1 fuzzy logic. Type-1 fuzzy sets have brought a degree of uncertainty for a linguistic expression of a field. However, since they are defined without any uncertainty in their parameters, precise values are obtained from these sets. Additionally, the uncertainties are generally coming from the noise in the measurements and the parameter changes due to the environmental and the operating conditions.

Type- 2 fuzzy sets were able to identify uncertainties as they could be expressed by the secondary membership function, and these sets take input membership values between 0 and 1. As seen in Figure 2 , a type-1 membership function has received multiple values when fuzzifier. Finally, with the combination of the entire embedded type- 1 fuzzy set, type- 2 membership function, which is limited by the upper membership function (UMF) and lower membership function (LMF), is obtained in a fuzzy area called FOU . Type-2 fuzzy set is expressed with Ã. If type- 2 membership function is $\mu_{\tilde{A}}(\mathrm{x}, \mathrm{u})$ and $0 \leq \mu_{\tilde{\mathrm{A}}}(\mathrm{x}, \mathrm{u}) \leq 1$ then type- 2 fuzzy set is expressed mathematically as in Equations (5) and (6).

$$
\begin{aligned}
& \tilde{A}=\left\{\left(\mathrm{x}, \mathrm{u},\left(\mu_{\tilde{\mathrm{A}}}(\mathrm{x}, \mathrm{u})\right) \mid \forall \mathrm{x} \in \mathrm{X}, \forall \mathrm{u} \in \mathrm{J}_{\mathrm{x}}^{\mathrm{u}} \subset[0,1]\right\}\right. \\
& \tilde{\mathrm{A}}=\int_{\mathrm{x} \in \mathrm{X}} \int_{\mathrm{u} \in \mathrm{JX}_{\mathrm{X}}} \mu_{\tilde{\mathrm{A}}}(\mathrm{x}, \mathrm{u}) /(\mathrm{x}, \mathrm{u}) \quad \mathrm{J} \subseteq[0,1]
\end{aligned}
$$

The expression in Equation (6) for the interval type-2 membership functions, where all secondary membership functions are equal to 1, turns into Equation (7) as shown below [7].

$$
\tilde{\mathrm{A}}=\int_{\mathrm{x} \in \mathrm{X}} \int_{\mathrm{u} \in \mathrm{Jx}} 1 /(\mathrm{x}, \mathrm{u}) \quad \mathrm{Jx} \subseteq[0,1]
$$

In figure 2, the primary membership functions of a type-2 fuzzy set used for interval type-2 fuzzy logic systems are defined on the $\mathrm{u}, \mathrm{x}$ axis. Each $\mathrm{x}$ values represent $\mathrm{u}$ membership degrees between 0 and 1 for upper membership function (UMF) and lower membership function (LMF). At the same time, it is clearly seen that the points of $x_{1}$ and $x_{2}$, which are secondary membership functions, are equal to 1 for ease of operation in interval type-2 fuzzy logic systems.

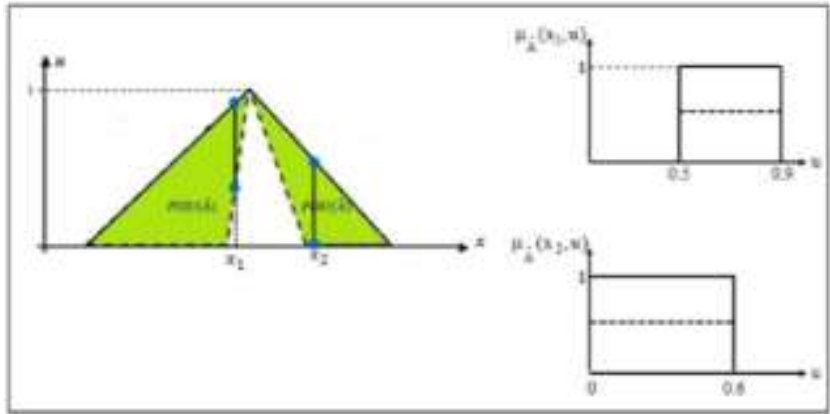

Fig 2. Type-2 membership function (FOU) and secondary membership function at point $\mathrm{x} 1, \mathrm{x} 2$

\subsection{Modelling of Sensorless Brushless DC Motor}

The complete block diagram of speed control of BLDC motor is shown in Fig. 3. This control structure consists of two control loops. The inner loop synchronizes the inverter gates signals with the electromotive forces. The outer loop controls the motor's speed by varying the $\mathrm{DC}$ bus voltage. The inverter which is connected to the dc supply feeds-controlled power to the motor. The magnitude and frequency of the inverter output voltage depends on the switching signals generated by the hysteresis controller.

This brushless motor is modeled as without sensors at a speed of 3000 RPM. In simulation, $0.25 \mathrm{Nm}$ full load and $0.20 \mathrm{Nm}$ was applied to the system in 0.5 seconds. Instead of sensors signal, back emf signals were used. Zero crossing detection circuit is used to convert back emf signals from BLDC motor to commutation signals. This is a voltage comparator circuit. Zero voltage is used to monitor the change in trepzoidal waveform from positive to negative or negative to positive. D type Flip Flop logic gates are used for commutation at zero point. Thanks to this block, signals equivalent to commutation times from hall sensors are generated. There is a 60 degree phase difference between the signals. Zero crossing detection block is shown in table.

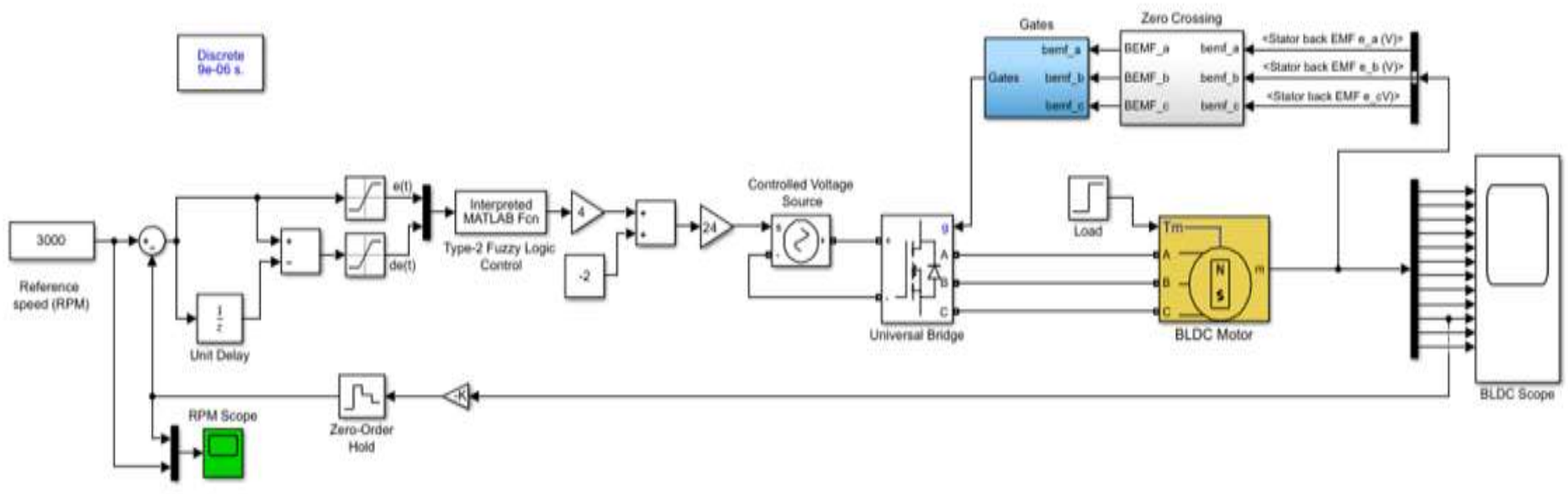

Fig 3. Simulation schematic of sensorless BLDC motor controlled by interval type-2 fuzzy logic controller in MATLAB/Simulink 


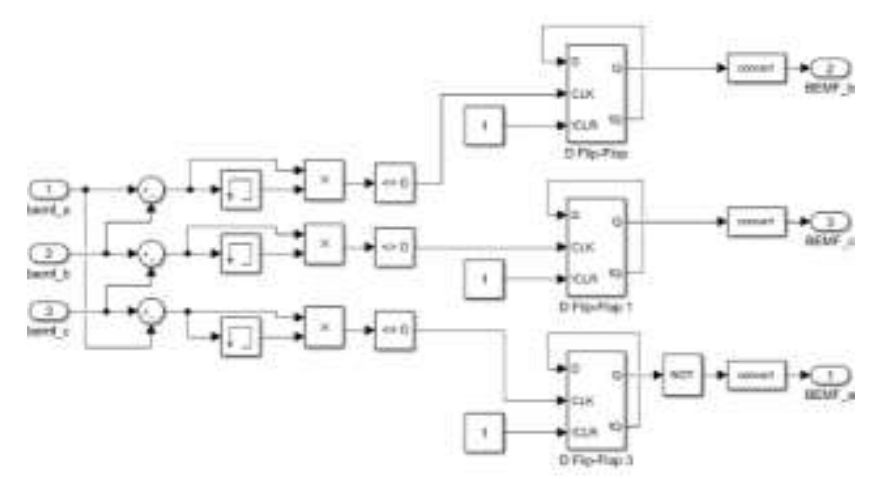

Fig 4. Zero Crossing Detector Block

3 phase inverter circuit is used to control BLDC motor. For this reason, the signal from the zero-crossing block is arranged in accordance with the 6 MOSFET gates in the circuit. Signals with the Gates block are used to synchronize the mosfet doors in the inverter synchronously. Gate block is shown in Table 3.

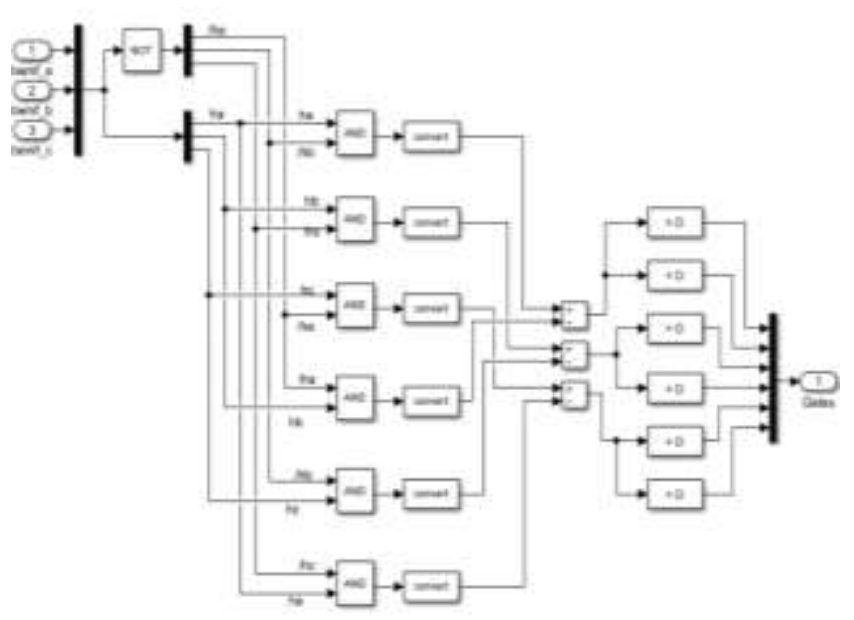

Fig 5. Gates Block

The triangular membership function is used for all variables shown in the type- 1 and type- 2 fuzzy logic controller. 5 different linguistic expressions are defined as fuzzy variables for the rule base. Linguistic expressions for output parameters and the input parameters (e (error), de (error change)); It is defined as NL (Negative Large), NZ (Negative Zero), ZZ (Zero), PZ (Positive Zero), PL (Positive Large).

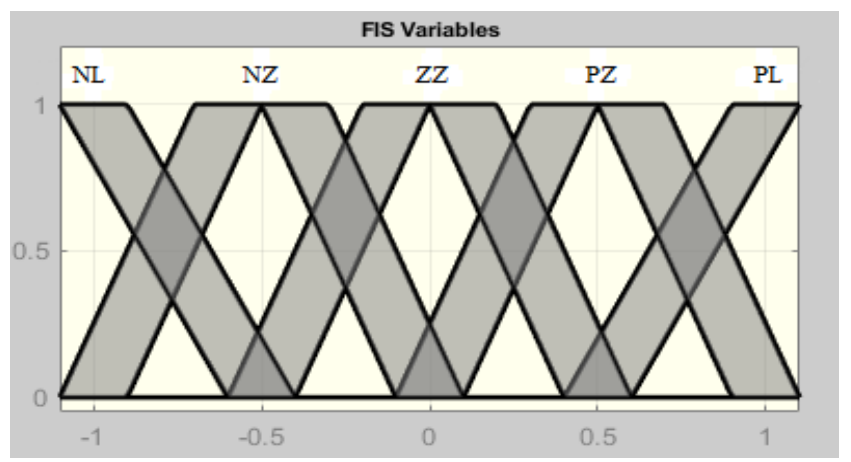

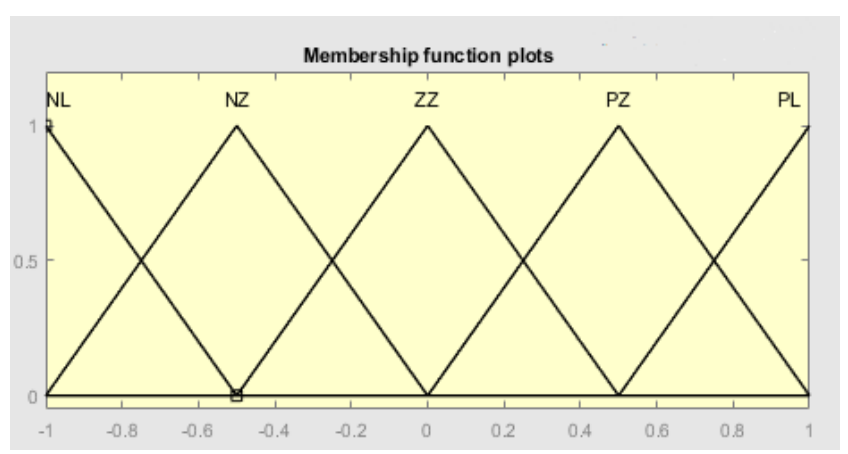

Fig 7. Membership functions for input parameters (e, de) of type-1 fuzzy logic controller

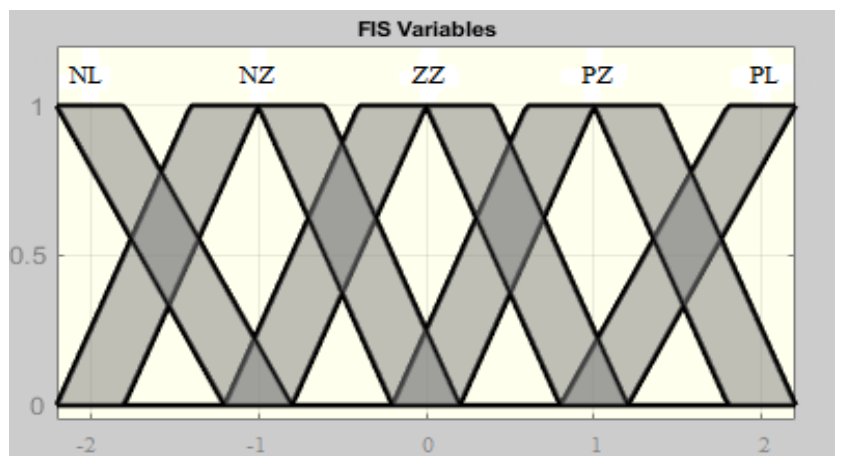

Fig 8. Membership functions for output of interval type-2 fuzzy logic controller

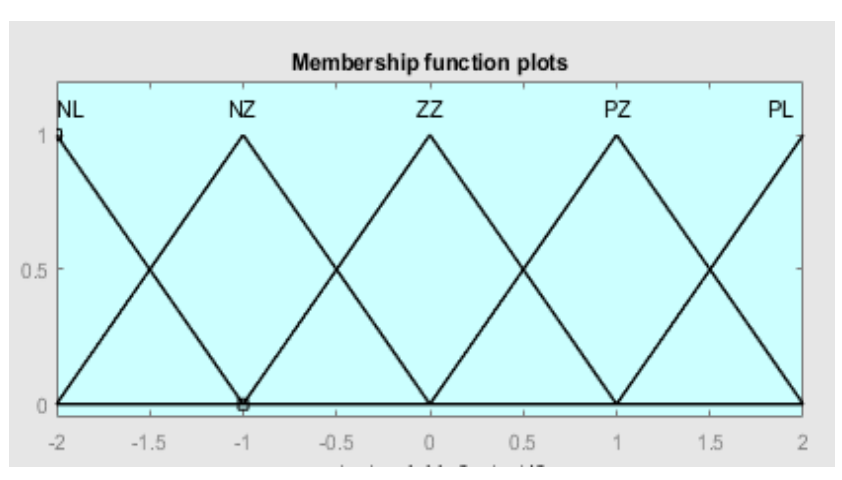

Fig 9. Membership functions for output of type-1 fuzzy logic controller

Table 2. Rule table for fuzzy logic controllers

\begin{tabular}{|c|c|c|c|c|c|}
\hline $\mathbf{N L}$ & $\mathrm{NL}$ & $\mathbf{N Z}$ & $\mathbf{Z Z}$ & $\mathbf{P Z}$ & $\mathbf{P L}$ \\
\hline $\mathbf{N Z}$ & $\mathrm{NL}$ & $\mathrm{NZ}$ & $\mathrm{NZ}$ & $\mathrm{ZZ}$ & $\mathrm{PZ}$ \\
\hline $\mathbf{Z Z}$ & $\mathrm{NZ}$ & $\mathrm{NZ}$ & $\mathrm{ZZ}$ & $\mathrm{PZ}$ & $\mathrm{PZ}$ \\
\hline $\mathbf{P Z}$ & $\mathrm{NZ}$ & $\mathrm{ZZ}$ & $\mathrm{PZ}$ & $\mathrm{PZ}$ & $\mathrm{PL}$ \\
\hline $\mathbf{P L}$ & $\mathrm{ZZ}$ & $\mathrm{PZ}$ & $\mathrm{PZ}$ & $\mathrm{PL}$ & $\mathrm{PL}$ \\
\hline
\end{tabular}

Fig 6. Membership functions for input parameters (e, de) of interval type-2 fuzzy logic controller 


\section{Experimental Results}

As shown in Figure 10, PI controller are arranged to create a stable system. Although the system appears stable, the controller responded late in terms of settling time rise time. In addition, the controller gave a more soft response when a full load was applied to the motor. This is an undesirable situation. Therefore, PID controller coefficients were rearranged for robust system response as $\mathrm{Kp}=1.5, \mathrm{Ki}=120$ and $\mathrm{Kd}=0.021$. Finally, the controller results are compared in Figure 11. Coefficients were determined using the PID tuning tool in Simulink.

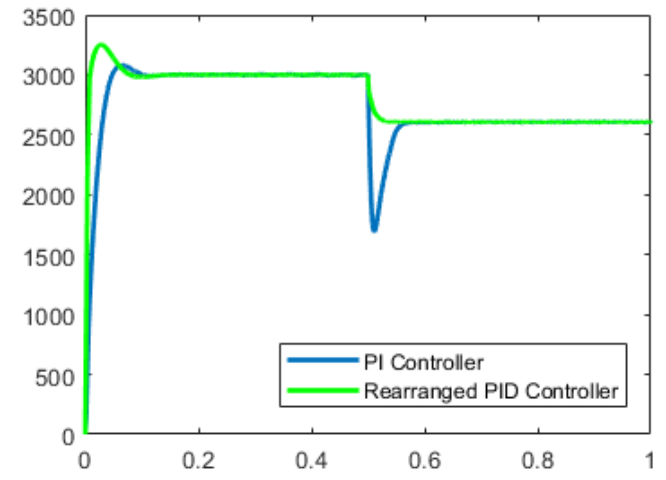

Fig 10. System response for $\mathrm{Kp}: 0.001$ and $\mathrm{Ki}=0.28 \mathrm{PI}$ coefficients

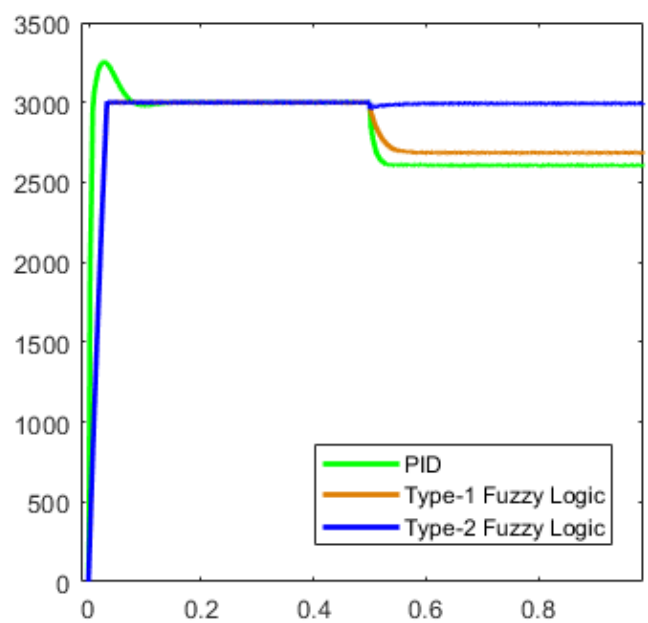

Fig 11. Speed performance results for 3 different controllers

In this simulation work, three different controllers as PID, Type-1 and Type-2 fuzzy logic was implemented. The sensorless brushless DC motor simulation was realized during $t=1$ second. When reaching the reference speed and under load, response of the controllers have been shown in Figure 11. Load has been applied to controllers at $\mathrm{t}=0.5$ seconds.

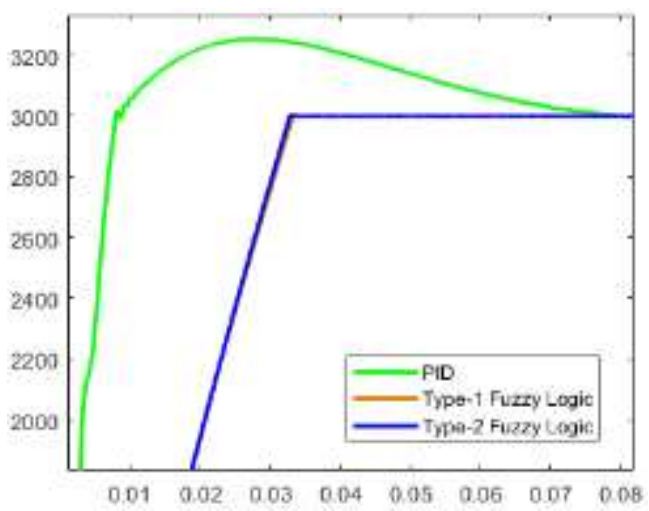

Fig 12. Response of 3 different controllers at reference speed value
Due to table 3, the results for PID controllers are undesirably high in terms of overshoot and settling time criteria. Also, PID controller seen responding to system in way non-linear due to changes in motor parameters.

Interval type-2 and type-1 fuzzy logic showed very close results when reach reference input value. Also, the percentage of overshoot is very low in both fuzzy logic controllers. Therefore, this parameter is neglected in fuzzy controllers. As seem table 3, in the system performed with interval type-2 fuzzy logic controller have observed relatively more suitable results according to type- 1 fuzzy logic controller in terms of the settling time, rise time, overshoot, peak time criteria.

Although both fuzzy controllers express the same linguistic field, the type-2 fuzzy controller was able to handle uncertainty better as it also provides a additional degree of fuzzy on its fuzzy sets. As a result, better system response was obtained in type- 2 fuzzy logic controller.

Table 3. Performance analysis for reference speed response

\begin{tabular}{|c|c|c|c|c|c|}
\hline Controller & $\begin{array}{c}\text { Settling } \\
\text { Time }\end{array}$ & $\begin{array}{c}\text { Rise } \\
\text { Time }\end{array}$ & Overshoot & $\begin{array}{c}\text { Peak } \\
\text { Value }\end{array}$ & $\begin{array}{c}\text { Peak } \\
\text { Time }\end{array}$ \\
\hline PID & $62.9 \mathrm{~ms}$ & $5.5 \mathrm{~ms}$ & $\% 8.406$ & 3252 & $\begin{array}{c}27.8 \\
\mathrm{~ms}\end{array}$ \\
\hline T1FL & $32.4 \mathrm{~ms}$ & $\begin{array}{c}26.4 \\
\mathrm{~ms}\end{array}$ & - & 3006 & $\begin{array}{c}33.4 \\
\mathrm{~ms}\end{array}$ \\
\hline T2FL & $32.1 \mathrm{~ms}$ & $\begin{array}{c}26.2 \\
\mathrm{~ms}\end{array}$ & - & 3007 & $33 \mathrm{~ms}$ \\
\hline
\end{tabular}

As shown in figure 13 above, when the full load of $0.25 \mathrm{Nm}$ was applied to the system at $\mathrm{t}=0.5$ second, the speed value for the PID controller exceed dropped and then stably responded at a speed lower than the reference speed. As shown in Table 4, According to applied load, undershoot value dropped at 15.68 percent. As a result, speed value dropped also to $2612 \mathrm{rpm}$. Also, PID controller more rapid load responded to applied load with fall time $=17.8 \mathrm{~ms}$. Load response for type-1 fuzzy logic is closer to reference speed than PID controller. The speed value has dropped to $2689 \mathrm{rpm}$ in way more stably in this system. Hence, undershoot value was decrease at 11.75 percent.

For the type-2 fuzzy logic controller, the speed value decreased to $2958 \mathrm{rpm}$ due to the load applied to the system at $\mathrm{t}=0.5$ seconds . The undershoot value also decreased proportionally by 0.48 percent. Then, the system response reached the reference value with $2.37 \mathrm{~ms}$ settling time. It is clear that type-2 fuzzy logic controller gives the best system response.

Table 4. Performance analysis for $0.25 \mathrm{Nm}$ full load

\begin{tabular}{|c|c|c|c|c|}
\hline Controller & $\begin{array}{c}\text { Settling } \\
\text { Time }\end{array}$ & $\begin{array}{c}\text { Fall } \\
\text { Time }\end{array}$ & Undershoot & Min Value \\
\hline PID & - & $17.8 \mathrm{~ms}$ & $\% 15.689$ & 2612 \\
\hline T1FL & - & $36.7 \mathrm{~ms}$ & $\% 11.759$ & 2689 \\
\hline T2FL & $2.376 \mathrm{us}$ & $26.2 \mathrm{~ms}$ & $\% 0.484$ & 2958 \\
\hline
\end{tabular}




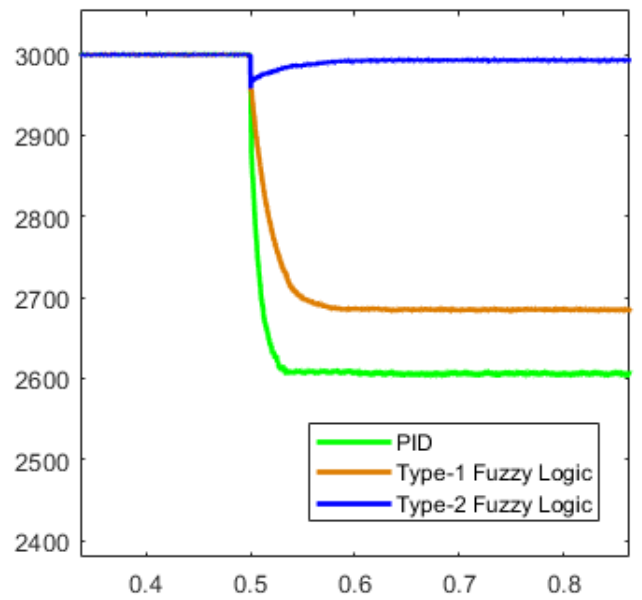

Fig 13. Speed response of 3 different controllers when $0.25 \mathrm{Nm}$ full load is applied

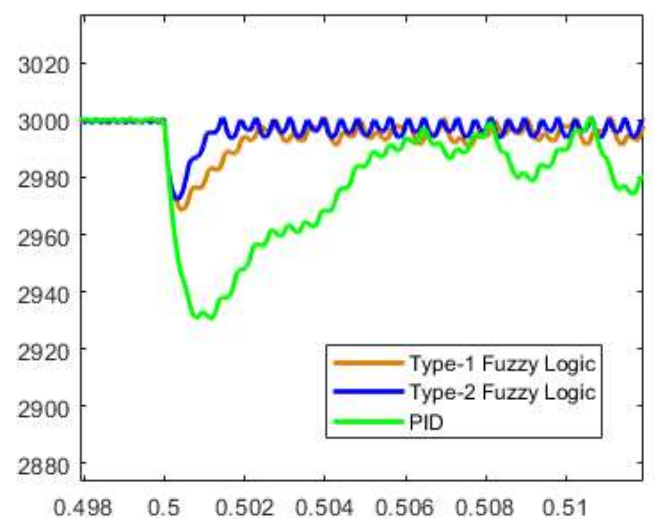

Fig 14. Speed response of 3 different controllers when $0.20 \mathrm{Nm}$ load is applied

When applied $0.20 \mathrm{Nm}$ load, controller response indicated in figure 14. For PID controller, speed of Brushless DC motor has dropped from 3000 to $2931 \mathrm{rpm}$ at $\mathrm{t}=0.5 \mathrm{~s}$. After this second, brushless DC motor reached more slowly to reference speed with 6.5 second settling time.

For type-1 fuzzy logic controller, speed of brushless DC motor has dropped from 3000 to $2968 \mathrm{rpm}$ at $\mathrm{t}=0.5 \mathrm{~s}$. Type- 1 fuzzy logic controller with $2.8 \mathrm{~ms}$ settling time responded in way more stable than PID controller.

With type-2 fuzzy logic controller, speed of brushless DC motor has dropped from 3000 to $2972 \mathrm{rpm}$ at $\mathrm{t}=0.5 \mathrm{~s}$. So, it clearly seen that type-2 fuzzy logic controller with 0.93 percent undershoot and $1.5 \mathrm{~ms}$ settling time gave the most stable response.

Thanks to interval fuzzy sets, type-2 fuzzy logic have obtained this results by making additional calculations on their own fuzzy sets.

Table 5. Performance analysis for $0.20 \mathrm{Nm}$ load

\begin{tabular}{|c|c|c|c|}
\hline & Settling Time & Undershoot & Min Value \\
\hline PID & $6.5 \mathrm{~ms}$ & $\% 2.3$ & 2931 \\
\hline T1FL & $2.8 \mathrm{~ms}$ & $\% 1.06$ & 2968 \\
\hline T2FL & $1.5 \mathrm{~ms}$ & $\% 0.93$ & 2972 \\
\hline
\end{tabular}

In addition, noisy load was also applied to the system at $t=0.5$ seconds. 3 different controllers gave a non-linear response in a noisy environment. According to the results, the PID controller was most affected by the noisy signal.

Type-1 fuzzy logic controller responded relatively more stable than PID controller. It has been understood that fuzzy sets, which are formed with linguistic expressions, analyze the noise signal better.

There are uncertainties in the system due to noise. In this case, type-2 fuzzy logic controller provided the best system response as shown figure 15 .

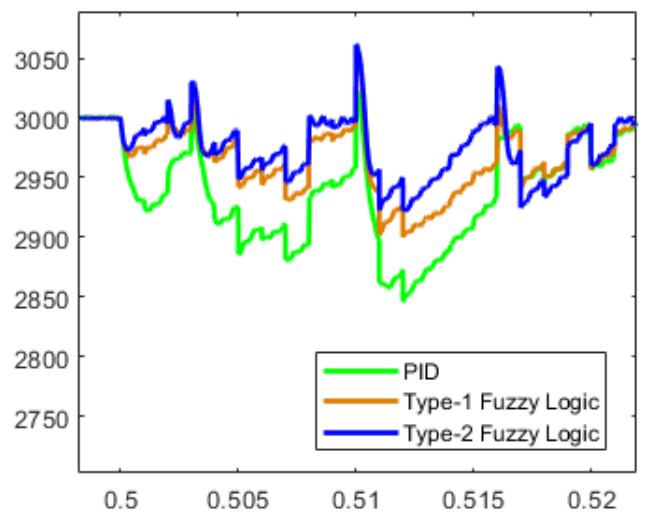

Fig 15. Speed response of 3 different controllers when $0.20 \mathrm{Nm}$ noise load is applied
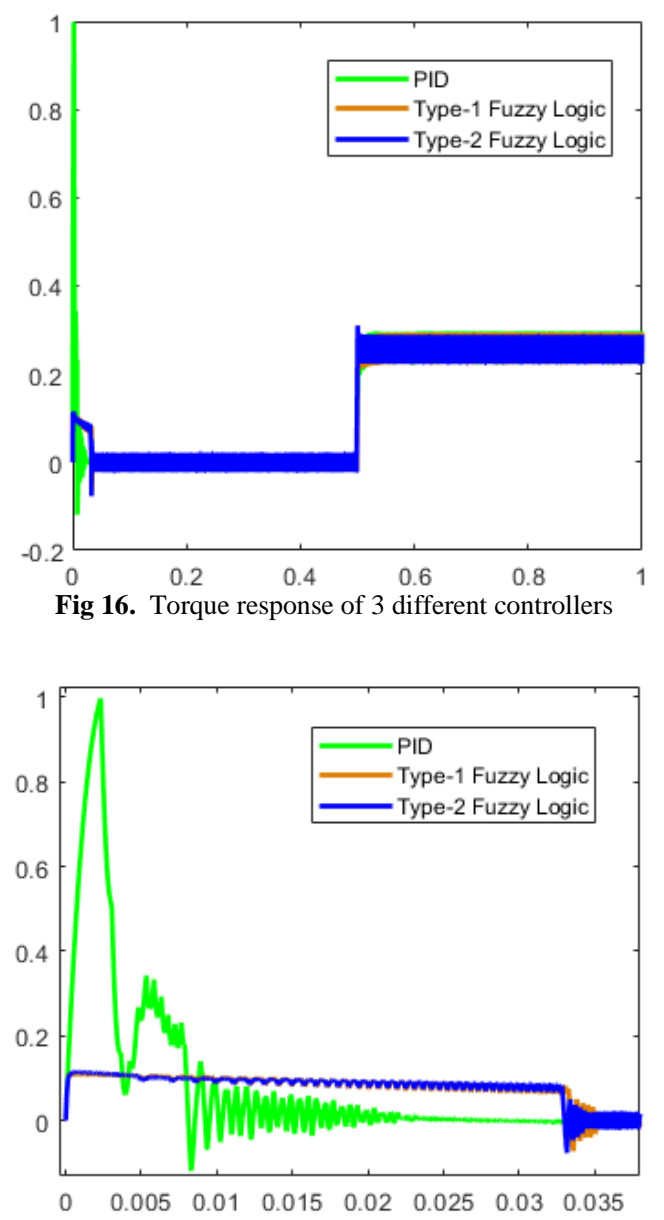

Fig 17. Initial torque response of 3 different controllers at reference speed value

As shown in figure 17 above, the starting torque for the PID controller showed the highest torque value. The torque value decreased over time until the system reached the reference speed and became stable.

In starting, type-1 fuzzy logic controller systems responded stably and at a lower torque value than the PID controller. When the system reached the reference value, the torque value suddenly by dropping responded stably again. 


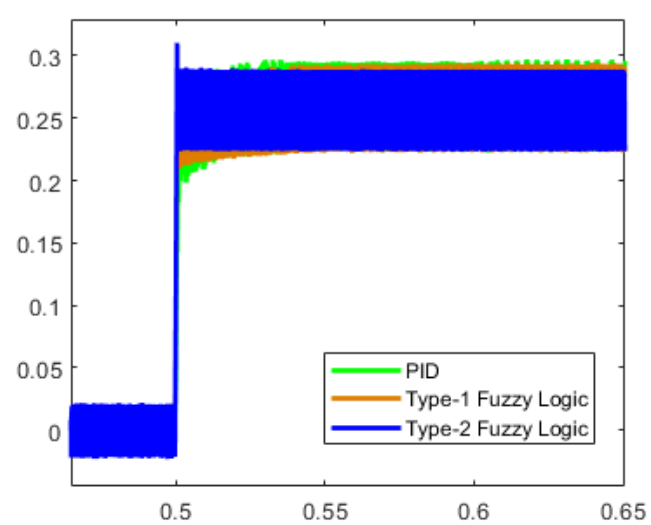

Fig 18. Torque response of 3 different controllers when full load is applied

In starting, type- 2 and type- 1 fuzzy controllers showed very similar results to each other. But, type-2 fuzzy controller system has shown its superiority by responding with low torque value and in a short time when reaching the reference speed value.

It's applied $0.25 \mathrm{Nm}$ torque load to 3 different controller. At $t=0.5$ second, the torque value for PID controller slowly increase. In addition, when the system compared to interval type- 2 and type- 1 fuzzy controllers, it responded late. After $\mathrm{t}=0.5$ second, the torque value was not stable. In this case, the system then tried to reach a stable response over time.

For the type- 1 fuzzy controller, at $\mathrm{t}=0.5$ second the system becomes stable by increasing the torque value. After $\mathrm{t}=0.5$ second, simulation completed with more high torque value than type-2 fuzzy logic controller.

The type-2 fuzzy controller responded quickly to system load. Although the torque value instantly increased in 0.5 seconds, it rapidly became stable. As shown figure 18, the lowest torque value range was seen in type-2 fuzzy logic controller.

\section{Conclusions}

For PID controller, coefficients were set as soft and robuts, and the results of both studies were presented. Since the structure of the brushless DC motor is non-linear, PID controller did not give the desired result.

Non-linear system structure complicates mathematical modeling. The fuzzy logic controllers can express a specific field linguistically, regardless of the mathematical model. Hence, the type-1 fuzzy logic controller has obtained a better system response than the PID controller.

According to the simulation results, Type- 1 and Type- 2 fuzzy logic controllers gave very close results to each other. Type- 2 fuzzy logic use same fuzzy sets with type-1 fuzzy logic. Additionally, type-2 fuzzy sets includes many embedded type-1 fuzzy sets. So, a stable system response is provided and uncertains can describe. Noise increases the uncertainty of the system. When noise is added to the system, it is seen the superiority of type- 2 fuzzy logic in simulation results. It was observed that can described better than type-1 fuzzy logic controller the uncertainties in the systems noisy and non-linear.

\section{References}

[1] Sonia Sunny, Rajesh K. (2013). Sensorless Control of BLDC Motor Drive Fed by Isolated DC-DC Converter. International Journal of Advanced Research in Electrical Electronics and Instrumentation Engineering vol. 2.
[2] Sadh, J. S. (2017). Sensorless zero back EMF method for in rotor position control of BLDC motor driver. Research Journal of Engineering, 6(7), 14-19.

[3] Dino Gu and Jemmey Huang. (2010). Sensorless BLDC motor control based on CY8C3866AXI. Cypress technical document.

[4] Singh, A. K., Chhabra, A., Chhillar, A., Ranga, A., \& Dahiya, R. (2017). Fuzzy logic based controllers for speed control of BLDC motor. Int. J. Res. Appl. Sci. Eng. Technol, 5(6).

[5] Davoudkhani, Iraj Faraji, and Mohsen Akbari. (2016). Adaptive speed control of brushless DC (BLDC) motor based on interval type-2 fuzzy logic. 2016 24th Iranian conference on electrical engineering (ICEE).

[6] Antão, R. (2017). Type-2 Fuzzy Logic: Uncertain Systems' Modeling and Control: Springer.

[7] Kelekçi, E. (2016). Development of Type-2 Fuzzy Logic Editor and Control of Flexible Joint Robot Arm. Kocaeli University, Institute of Science.

[8] Kayacan, Erdal, et al. (2010). Design of an adaptive interval type-2 fuzzy logic controller for the position control of a servo system with an intelligent sensor. International conference on fuzzy systems.

[9] Jamshidi, J., \& Tohidi, H. (2016). Sensorless control strategy for brushless DC motor drives based on sliding mode observer. International Journal of Computer Science and Network Security (IJCSNS), 16(12), 43.

[10] Chowdhury, D., Chattopadhyay, M., \& Roy, P. (2013). Modelling and simulation of cost effective sensorless drive for brushless DC motor. Procedia Technology, 10, 279-286.

[11] S.Patel, Kaushal \& B.Ahir, Jignesha. (2016). Speed Control of Sensorless Brushless Direct Current (BLDC) Motor using Back EMF. International Journal of Engineering Trends and Technology. 35, 600604.

[12] Cunkas, M., \& Aydoğdu, O. (2010). Realization of fuzzy logic controlled brushless dc motor drives using Matlab/Simulink. Mathematical and Computational Applications, 15(2), 218-229.

[13] Kumar, P., \& Soman, S. (2015). Simulation of Four Quadrant Operation of Sensorless BLDC Motor. IOSR Journal of Electrical and Electronics Engineering,34-42.

[14] Zero Crossing Detector Circuit and Working. [Online]. Available: https://www.elprocus.com/zero-crossing-detector-circuit-andworking/

[15] Saritas, İ., Ozkan, I. A., \& Herdem, S. (2011). The Control Of A Dc Motor By Fuzzy Logic Controller. Engineering Sciences, 6(2), 533541. 